\title{
Industrial-Scale Decontamination Procedure Effects on the Content of Acaricides, Heavy Metals and Antioxidant Capacity of Beeswax
}

\author{
María D. Navarro-Hortal ${ }^{1}$, Francisco J. Orantes-Bermejo ${ }^{2}$, Cristina Sánchez-González ${ }^{1}{ }^{\circledR}$, \\ Alfonso Varela-López ${ }^{1}{ }^{\mathbb{D}}{ }$, Francesca Giampieri ${ }^{3} \mathbb{D}$, Cristina Torres Fernández-Piñar ${ }^{2}$, \\ Josep Serra-Bonvehí ${ }^{4}$, Tamara Y. Forbes-Hernández ${ }^{5}$ (D) , Patricia Reboredo-Rodríguez ${ }^{5}$, \\ Juan Llopis ${ }^{1}$, Pilar Aranda ${ }^{1}$, Maurizio Battino ${ }^{3,5}$ and José L. Quiles ${ }^{1, *(D)}$ \\ 1 Institute of Nutrition and Food Technology "José Mataix Verdú", Department of Physiology, \\ Biomedical Research Center, University of Granada, Avda del Conocimiento sn., \\ 18100 Armilla, Granada, Spain; mdnavarro@ugr.es (M.D.N.-H.); crissg@ugr.es (C.S.-G.); \\ alvarela@ugr.es (A.V.-L.); jllopis@ugr.es (J.L.); paranda@ugr.es (P.A.) \\ 2 Apinevada Analytical Laboratory of Bee Products, Barrancos s/n, Lanjarón, 18420 Granada, Spain; \\ director@apinevada.com (F.J.O.-B.); calidad@apinevada.com (C.T.F.-P.) \\ 3 Dipartimento di Scienze Cliniche Specialistiche ed Odontostomatologiche-Sez, Biochimica, \\ Università Politecnica delle Marche, Ancona, 60131 Ancona, Italy; f.giampieri@staff.univpm.it (F.G.); \\ mbattino@mta01.univpm.it (M.B.) \\ 4 Research \& Development Department, Mielso, S.A., Pol. Industrial 'El Mijares', C/. Industria 1, \\ 12550 Almassora (Castelló), Spain; serrjosep@gmail.com \\ 5 Nutrition and Food Science Group, Department of Analytical and Food Chemistry, CITACA, CACTI, \\ University of Vigo, 36310 Vigo, Spain; tamaraforbe@gmail.com (T.Y.F.-H.); preboredo@uvigo.es (P.R.-R.) \\ * Correspondence: jlquiles@ugr.es; Tel.: +34-958241000 (ext. 20316)
}

Received: 1 March 2019; Accepted: 16 April 2019; Published: 17 April 2019

\begin{abstract}
Beeswax is useful for the beekeeping sector but also for the agro-food, pharmaceutical or cosmetics sectors. Frequently, this bee product is contaminated with pesticides reducing its utility and causing the decline in its market. This study aimed to prove the effectiveness of an industrial-scale decontamination method in removing acaricides from beeswax. Chlorfenvinphos and coumaphos decrease was higher than $90 \%$, whereas tau fluvalinate decrease was only $30 \%$. No changes were observed in the beeswax content of hydrocarbons and monoesters, whereas a decrease in the concentrations of $\mathrm{Ca}, \mathrm{Fe}, \mathrm{Zn}, \mathrm{Hg}, \mathrm{Mn}$ and $\mathrm{P}$, and an increase in the concentrations of As and $\mathrm{Si}$ were found after the decontamination. Filtration reduced total phenolics, flavonoids and the antioxidant capacity of the lipophilic extract. These results demonstrate that the industrial method used was as effective as the method previously tested on a laboratory scale. The study also contributes to a better knowledge and characterization of beeswax, specially related to trace and ultra-trace elements and antioxidant capacity. Moreover, it offers the chance to further develop a method to effectively detect wax adulterations based on the chemical elements profile.
\end{abstract}

Keywords: beeswax decontamination; pesticides; monoesters; hydrocarbons; chemical elements; flavonoids; total phenols; adulteration

\section{Introduction}

Beeswax is a natural honeybee product endogenously secreted by specific glands of worker honeybees [1]. Beeswax is vital for the honeybee colony because it is used as building material for its comb cells where nectar and honey are stored [2]. Beeswax is an extremely complex mixture of lipophilic 
nature composed of esters of fatty acids, hydrocarbons, and other minor substances [1,3]. Frequently, beeswax is contaminated with residues of pesticides, such as pyrethroid and organophosphate acaricides, which are used against the mite Varroa destructor. This mite is a parasite of bees that is currently considered the biggest threat to apiculture [4]. The long-term application of acaricides leads to the deposition of non-volatile and lipophilic residues, which accumulate especially in beeswax. Wax is collected and reused in apiculture and in other sectors, such as food, chemical, pharmaceutical or cosmetics sectors. In the agri-food industry, beeswax is used as food additive (E901), as a glazing agent in the preparation of pastries, for the treatment of some fruits, as food supplement, and as a flavor carrier [5]. Beeswax plays a role as binder, thickener, drug carrier and release retardant in pharmaceutical preparations [6]. However, contamination devaluates recycled wax, causes health problems when using wax for food or other purposes, and affects bee colonies, therefore, contamination has led to a gradual decline in the beeswax market in recent years.

Recently, our research group has tested a wax decontamination protocol [7] at a pilot scale. This new protocol sought to avoid the use of chemical agents for the bleaching of used beeswax, since these agents altered the composition of the wax and barely managed to reduce its degree of contamination [7]. The results obtained were promising, with decreases in the concentrations of highly representative chemicals. The present study digs deeper in the above-mentioned method, but now at an industrial scale. Although we must continue developing methodologies that further reduce the level of pesticides, it is also important to elucidate if any technology reducing the presence of various toxic compounds can result in changes in the chemical composition of the beeswax. The objective of the present study was to test the effectiveness of the decontamination process at an industrial scale and its effects on wax composition. For this purpose, the composition of different samples were investigated and the characterization of beeswax before and after being subjected to decontamination was performed. In particular, the study focused on the composition of monoester and hydrocarbon waxes, the content of chemical elements, including trace and ultra-trace elements, as well as the antioxidant capacity and total phenolic and flavonoid contents of hydrophilic and lipophilic extracts of the waxes.

\section{Results and Discussion}

\subsection{Pesticide Content}

The main objective of subjecting beeswax to the filtration process was to reduce the levels of pesticides. Therefore, the negative impact of pesticides on human health and on the hives would be prevented. Three types of acaricides were evaluated in beeswax samples. The initial and final concentrations of these three pesticides are specified in Table 1.

Table 1. Pesticide content (ppb) and percentage reduction (\%) in beeswax before and after subjecting the samples to the industrial method of decontamination.

\begin{tabular}{cccc}
\hline Compounds & Initial Contamination (ppb) & Final Contamination (ppb) & Percentage Reduction \\
\hline \multirow{2}{*}{ Chlorfenvinphos $(\mathrm{n}=3)$} & 1785 & 977 & $45.3 \%(1 \mathrm{cycle} *)$ \\
& 685 & 59 & $91.4 \%(2 \mathrm{cycles})$ \\
Coumaphos $(\mathrm{n}=3)$ & 1398 & 100 & $92.8 \%(2 \mathrm{cycles})$ \\
& 14126 & 10914 & $22.8 \%(1 \mathrm{cycle})$ \\
tau fluvalinate & $* *$ \\
& 8758 & 763 & $91.3 \%(2 \mathrm{cycles})$ \\
& 1788 & 58 & $96.7 \%(2 \mathrm{cycles})$ \\
& 2113 & 1721 & $18.5 \%(1 \mathrm{cycle})$ \\
\hline
\end{tabular}

* The number of cycles ( 1 cycle or 2 cycles) refers to the number of times that the same sample has been subjected consecutively to the filtering process. ${ }^{* *}$ In the case of tau fluvalinate, only two samples were analyzed after verifying that the percentage of elimination in the beeswax did not exceed 30\%, similarly to Bonvehi and Orantes-Bermejo [7].

The studied compounds were chlorfenvinphos, coumaphos and tau fluvalinate, all of which are the most common acaricides used by Spanish beekeepers against Varroa destructor [8-11]. These compounds 
are also used in other countries such as USA [12], France [13], Belgium [14] and Italy [15]. In the first cycle of filtration, the reduction of each compound was around $20 \%$ except for chlorfenvinphos, which the reduction exceeded $40 \%$. Nevertheless, the percentage reduction of organophosphate chlorfenvinphos and coumaphos in the sample was greater than $90 \%$ after the second cycle of filtration. Two cycles of filtration could only eliminate 636 out of $2113 \mathrm{ppb}$ of tau fluvalinate, which led to a $30 \%$ of reduction. These percentage reductions are in the same range as those reported in previous studies on Spanish beeswax [7], on palm oil at laboratory-scale [16] and on industrial edible oils [17] and are consistent with other studies performed on olive oil [18]. These findings highlight the relevance of the molecule type and its liposolubility in the filtration process, with the pyrethroid pesticide the most lipophilic and the least eliminated. Furthermore, the incomplete elimination of organophosphates could be explained by their competition with monoesters for adsorption sites [7].

Consistent with these results, the industrial method tested for decontamination displayed its effectiveness to remove pesticide contents in beeswax samples, especially organophosphate acaricides. Therefore, the industrial reproducibility of the decontamination method performed at laboratory scale by Bonvehi \& Orantes-Bermejo [7] is proven in the present study.

\subsection{Hydrocarbons and Monoesters Content}

Hydrocarbons and monoesters are two of the main groups constituting to beeswax. Their identification and quantification were established by gas chromatography-mass spectrometry (GC-MS). The beeswax composition regarding the content of aliphatic hydrocarbons was not modified by the filtration process. The hydrocarbons $\mathrm{H}_{19}-\mathrm{H}_{44}$ were evaluated and there were no significant differences between the existent amounts before and after filtration, as shown in Table 2. Among these substances, $\mathrm{H}_{27}$ stood out as being the major hydrocarbon, followed by $\mathrm{H}_{29}, \mathrm{H}_{31}, \mathrm{H}_{25}$ and other minor hydrocarbons, such as $\mathrm{H}_{33}{ }^{*}, \mathrm{H}_{31}{ }^{*}, \mathrm{H}_{23}$, all of them with values above one. These findings are consistent with those found in other studies $[3,9,19]$. Besides the saturated form, beeswax contained unsaturated structures of $\mathrm{H}_{31}, \mathrm{H}_{33}$ and $\mathrm{H}_{35}$.

The monoesters content of the beeswax samples before and after the filtration process expressed in percentage is detailed in Table 3. As it can be observed, the filtration did not change the amount of monoesters, which are important components of the beeswax, mainly saturated wax esters. The $\mathrm{C}_{40}$ to $C_{50}$ monoesters with an even number of carbon atoms were quantified and the presence of an unsaturated form was found for all of them. The most abundant monoester was $\mathrm{C}_{46}$, followed in abundance by $\mathrm{C}_{40}, \mathrm{C}_{48}, \mathrm{C}_{44}$ and $\mathrm{C}_{42}$. Taking into account the $100 \%$ sum of hydrocarbons and monoesters, $51.6 \%$ correspond to hydrocarbons and $48.4 \%$ correspond to monoesters. These percentages are similar to those determined by Maia \& Nunes [19].

Table 2. Aliphatic hydrocarbons content (\%) in beeswax before and after the filtration process.

\begin{tabular}{ccc}
\hline Abbreviated Formula & Unfiltered Beeswax $(\mathbf{n}=\mathbf{3})$ & Filtered Beeswax $(\mathbf{n}=\mathbf{3})$ \\
\hline & Mean \pm SEM & Mean \pm SEM \\
\hline H19 & $0.143 \pm 0.004$ & $0.139 \pm 0.005$ \\
H20 & $0.273 \pm 0.083$ & $0.485 \pm 0.080$ \\
H21 & $0.419 \pm 0.005$ & $0.393 \pm 0.019$ \\
H22 & $0.135 \pm 0.012$ & $0.113 \pm 0.004$ \\
H23 & $2.979 \pm 0.049$ & $2.946 \pm 0.069$ \\
H24 & $0.186 \pm 0.002$ & $0.169 \pm 0.001$ \\
H25 & $5.306 \pm 0.103$ & $5.293 \pm 0.077$ \\
H26 & $0.382 \pm 0.004$ & $0.360 \pm 0.007$ \\
H27 & $15.473 \pm 0.245$ & $15.279 \pm 0.139$ \\
H28 & $0.372 \pm 0.020$ & $0.334 \pm 0.009$ \\
\hline
\end{tabular}


Table 2. Cont.

\begin{tabular}{ccc}
\hline Abbreviated Formula & Unfiltered Beeswax $(\mathbf{n}=\mathbf{3})$ & Filtered Beeswax $(\mathbf{n}=\mathbf{3})$ \\
\hline H29 & $9.300 \pm 0.116$ & $9.158 \pm 0.215$ \\
H30 & $0.304 \pm 0.011$ & $0.277 \pm 0.006$ \\
H31:1 & $2.762 \pm 0.015$ & $2.362 \pm 0.262$ \\
H31 & $7.179 \pm 0.148$ & $7.111 \pm 0.130$ \\
H32 & $0.351 \pm 0.018$ & $0.377 \pm 0.024$ \\
H33:1 & $4.102 \pm 0.104$ & $4.076 \pm 0.104$ \\
H33 & $0.737 \pm 0.006$ & $0.736 \pm 0.019$ \\
H34 & $0.115 \pm 0.004$ & $0.109 \pm 0.008$ \\
H35:1 & $0.213 \pm 0.013$ & $0.238 \pm 0.012$ \\
H35 & $0.418 \pm 0.023$ & $0.259 \pm 0.111$ \\
H36 & $0.106 \pm 0.053$ & $0.185 \pm 0.028$ \\
H37 & $0.077 \pm 0.017$ & $0.106 \pm 0.010$ \\
H38 & $0.009 \pm 0.009$ & $0.063 \pm 0.023$ \\
H39 & $0.049 \pm 0.022$ & $0.039 \pm 0.010$ \\
H40 & $0.097 \pm 0.005$ & $0.118 \pm 0.028$ \\
H41 & $0.041 \pm 0.025$ & $0.067 \pm 0.018$ \\
H42 & $0.029 \pm 0.008$ & $0.023 \pm 0.008$ \\
H43 & $0.043 \pm 0.015$ & $0.020 \pm 0.010$ \\
H44 & $0.008 \pm 0.004$ & $0.012 \pm 0.008$ \\
LH & $51.609 \pm 0.805$ & $50.848 \pm 0.714$ \\
\hline
\end{tabular}

$\Sigma \mathrm{H}$ represents the sum of all hydrocarbons detected.

Table 3. Monoesters in beeswax (\%) before and after the filtration process.

\begin{tabular}{cccc}
\hline Abbreviated Formula & Compound Name & Unfiltered Beeswax $(\mathbf{n}=\mathbf{3})$ & Filtered Beeswax $(\mathbf{n}=\mathbf{3})$ \\
\hline & & Mean \pm SEM & Mean \pm SEM \\
\hline C40 & Ethyl tetracontanoate & $10.2 \pm 0.1$ & $10.3 \pm 0.1$ \\
C40:1 & Ethyl tetracontenoate & $0.00 \pm 0.00$ & $0.03 \pm 0.01$ \\
C42 & Ethyl dotetracontanoate & $5.9 \pm 0.1$ & $5.8 \pm 0.1$ \\
C42:1 & Ethyl dotetracontenoate & $0.23 \pm 0.01$ & $0.22 \pm 0.03$ \\
C44 & Ethyl tetratetracontanoate & $6.5 \pm 0.1$ & $6.7 \pm 0.1$ \\
C44:1 & Ethyl tetratetracontenoate & $0.2 \pm 0.1$ & $0.2 \pm 0.1$ \\
C46 & Ethyl hexatetracontanoate & $15.3 \pm 0.9$ & $15.4 \pm 0.9$ \\
C46:1 & Ethyl hexatetracontenoate & $0.11 \pm 0.06$ & $0.11 \pm 0.01$ \\
C48 & Ethyl octatetracontanoate & $8.2 \pm 0.1$ & $8.5 \pm 0.1$ \\
C48:1 & Ethyl octatetracontenoate & $0.32 \pm 0.01$ & $0.41 \pm 0.14$ \\
C50 & Ethyl pentacontanoate & $0.69 \pm 0.08$ & $0.65 \pm 0.05$ \\
C50:1 & Ethyl pentacontenoate & $0.70 \pm 0.11$ & $0.73 \pm 0.02$ \\
CC & Total monoesters & $48.391 \pm 0.805$ & $49.152 \pm 0.714$ \\
\hline
\end{tabular}

Chemical composition of beeswax is important in conferring the appropriate mechanical properties to this natural wax, especially esters of fatty acids. In addition, the alkenes, which are present in much smaller quantities than their respective alkanes, seem to have a signaling and recognition function for bees [2]. The industrial process of decontamination does not affect the basic composition of beeswax; therefore, these properties and functions will not be altered, which have special importance considering that the main use of recycled wax is to build honeycombs again.

\subsection{Chemical Elements Composition}

The presence of heavy metals and trace and ultra-trace elements in honeybees, honey or pollen is being well-studied [20-22] because of their use in the food industry. Furthermore, the analysis of this type of elements in beeswax is infrequent due to the fact that beeswax is not consumed; however, it is important to control the concentration of these elements because beeswax is used in other areas such as biomedicine or in the cosmetic industry. Bee products are useful tools for collecting information about environmental contamination with toxic metals [23-26]. More precisely, beeswax combs behave like a 
sink because of the specific lipid-based chemical composition of beeswax [2]. Trace and ultra-trace analysis of honey could be used to guarantee its place of origin [27] or to assess its quality [28].

In this particular case, the determination of chemical elements using inductively coupled plasma mass spectrometry (ICP-MS) had, as a main objective, the assessment of possible changes in the composition of wax as a consequence of the decontamination process. The results detailed in Table 4 show the difference between the chemical element composition of beeswax after subjecting it to a filtration process compared to its composition before this process. Initially, some analyzed elements, such as $\mathrm{Cr}, \mathrm{Cu}, \mathrm{Mo}, \mathrm{Ni}$ and $\mathrm{Sc}$, were absent. No shifts were found in the presence of the minerals $\mathrm{Al}, \mathrm{Au}, \mathrm{Cd}, \mathrm{Co}, \mathrm{Cr}, \mathrm{Cu}, \mathrm{K}, \mathrm{Mg}, \mathrm{Mo}, \mathrm{Ni}, \mathrm{Pb}, \mathrm{Sc}, \mathrm{Se}, \mathrm{V}$ and $\mathrm{Y}$. However, the concentrations of As, $\mathrm{Ca}, \mathrm{Fe}, \mathrm{Hg}, \mathrm{Mn}, \mathrm{P}, \mathrm{Si}$ and $\mathrm{Zn}$ were altered. In particular, a significant decrease in $\mathrm{Ca}, \mathrm{Fe}$, and $\mathrm{Zn}$, and a minor decrease in $\mathrm{Hg}, \mathrm{Mn}$ and $\mathrm{P}$ were found, whereas a significant increase in As and $\mathrm{Si}$ was found. The largest change produced by the filtration process was found in calcium. The expected changes were a decrease in the content of chemical elements as a consequence of losses occurred during the filtration process through the bleaching earth. Nevertheless, an increase in As and $\mathrm{Si}$ was found. The increase in Si and As observed in the waxes after their filtration process is due to the use of diatomaceous earth as part of the filtering system. Indeed, Si represents more than $85 \%$ of diatomaceous earth composition [29], and it is possible that it is partly transferred to the filtered matrix. Furthermore, arsenic may represent around 0.2 to $0.5 \%$ of diatomaceous earth composition [29]. The transfer of arsenic that occurs during the filtration process with diatomaceous earth of alcoholic beverages has been described [30]. These authors [30] suggest the reduction of the transfer of As by selecting diatomaceous earth with low concentration of heavy metals and even pre-washing the filter before its use to filter the studied matrix. The concentrations of Si and As in the filtered waxes are within the healthy intake ranges established in the guidelines for tolerable intakes issued by the European Food Safety Authority [31].

The impact of the pesticide removal process was constrained to a low number of chemical elements: the concentrations of only eight out of twenty-three analyzed elements were modified. Regarding the main heavy metals used as indicators of environmental pollution ( $\mathrm{As}, \mathrm{Cd}, \mathrm{Hg}$ and $\mathrm{Pb}$ ), the treatment achieved the decrease in $\mathrm{Hg}$. Consistent with the results obtained in other studies, concentrations of As found in pre-filtered wax and concentrations of $\mathrm{Zn}$ existing in post-filtered wax were similar to those found by other authors [21], whereas the other elements studied were in the same range of magnitude, although their values were different, which could be explained by the different geographical origins. Contamination with heavy metals could affect honeybee brood development, after-emergence vitality, queen productivity or longevity of adult bees [25], so the decrease in $\mathrm{Hg}$ is a positive effect considering the toxicity of this element for bees and human beings. The decrease in other minerals such as $\mathrm{Mn}$ is also beneficial because its ingestion by bees could alter brain levels of biogenic amine, and the exposure to this metal negatively affects the foraging behavior of honeybees [32]. The available information concerning the presence or the effects of chemical elements not considered environmental pollutants ( $\mathrm{Ca}, \mathrm{P}, \mathrm{Si}, \mathrm{Fe}$, etc.) on beeswax is poor, so it is not possible to go into more details in this regard.

In view of the results obtained in the analysis of the chemical elements in the waxes, the possibility of using the chemical elements profile to determine adulteration of beeswax with other waxes was raised. Today, adulteration of beeswax with other wax can be detected very accurately because the adulteration products affect to the common concentration of beeswax components or because of the presence of no characteristic compounds of this beehive product. For this purpose, the mineral elements contents of carnauba wax, shell microcrystalline and paraffin p600, the main waxes used for beeswax adulteration, were analyzed. Figure 1 shows the mineral concentrations in the mentioned waxes. As observed, striking differences exist between waxes regarding the chemical elements profiles, especially in the case of $\mathrm{Ca}, \mathrm{Fe}, \mathrm{K}, \mathrm{Mg}, \mathrm{P}$ and $\mathrm{Si}$, standing out as the high content of minerals in carnauba wax. The interesting differences observed in the profile of chemical elements between the different waxes analyzed raises the possibility of using this method, alone or in combination with others, to analyze possible adulterations of beeswax with carnauba wax or maybe another. In the present 
study, an exhaustive analysis of this possibility has not been made. Although mineral and carnauba waxes have been used to make comparisons, these have not been subjected to the filtering process, for example. It is therefore a hypothesis that needs to be developed. In fact, to be useful, it would have to allow discerning if the changes in the profile of chemical elements are due to adulteration with other waxes or to some other process used.

Table 4. Chemical elements in unfiltered and filtered beeswax samples. Results are expressed in $\mathrm{ppm}(\mathrm{mg} / \mathrm{kg})$.

\begin{tabular}{ccc}
\hline & Unfiltered Beeswax $(\mathbf{n}=\mathbf{3})$ & Filtered Beeswax $(\mathbf{n}=\mathbf{3})$ \\
\hline Element & Mean \pm SEM & Mean \pm SEM \\
\hline $\mathrm{Al}$ & $9.9 \pm 2.2$ & $7.8 \pm 3.5$ \\
$\mathrm{As}$ & $0.015 \pm 0.002$ & $0.048 \pm 0.023^{*}$ \\
$\mathrm{Au}$ & $1.6 \pm 1.0$ & $1.3 \pm 1.1$ \\
$\mathrm{Ca}$ & $158 \pm 72$ & $37 \pm 12^{*}$ \\
$\mathrm{Cd}$ & $0.020 \pm 0.011$ & $0.011 \pm 0.005$ \\
$\mathrm{Co}$ & $0.004 \pm 0.004$ & $0.000 \pm 0.000$ \\
$\mathrm{Cr}$ & $0.000 \pm 0.000$ & $0.000 \pm 0.000$ \\
$\mathrm{Cu}$ & $0.000 \pm 0.000$ & $0.000 \pm 0.000$ \\
$\mathrm{Fe}$ & $20.7 \pm 2.2$ & $0.6 \pm 0.6^{*}$ \\
$\mathrm{Hg}$ & $1.7 \pm 1.3$ & $0.1 \pm 0.1^{*}$ \\
$\mathrm{~K}$ & $88 \pm 6$ & $65 \pm 27$ \\
$\mathrm{Mg}$ & $21.2 \pm 3.2$ & $67.9 \pm 41.5$ \\
$\mathrm{Mn}$ & $0.51 \pm 0.17$ & $0.14 \pm 0.09^{*}$ \\
$\mathrm{Mo}$ & $0.000 \pm 0.000$ & $0.000 \pm 0.000$ \\
$\mathrm{Ni}$ & $0.000 \pm 0.000$ & $0.000 \pm 0.000$ \\
$\mathrm{P}$ & $47.3 \pm 1.7$ & $27.7 \pm 11.2^{*}$ \\
$\mathrm{~Pb}$ & $3.5 \pm 2.1$ & $2.9 \pm 2.1$ \\
$\mathrm{Sc}$ & $0.000 \pm 0.000$ & $0.000 \pm 0.000$ \\
$\mathrm{Se}$ & $0.015 \pm 0.012$ & $0.000 \pm 0.000$ \\
$\mathrm{Si}$ & $1.10 \pm 1.10$ & $33.41 \pm 33.41^{*}$ \\
$\mathrm{~V}$ & $0.021 \pm 0.004$ & $0.044 \pm 0.021$ \\
$\mathrm{Y}$ & $0.007 \pm 0.000$ & $0.008 \pm 0.002$ \\
$\mathrm{Zn}$ & $10.3 \pm 0.5$ & $1.3 \pm 0.3^{*}$
\end{tabular}

* Statistically significant differences $(p<0.05)$ between unfiltered and filtered beeswax.

In addition to the chemical element profile proposed here, other aspects of the beeswax composition are used to detect adulterations. The total amount of hydrocarbons and monoesters, and the relative proportion of each of them, revealed the purity of beeswax of the tested samples $[9,19,33]$. Hydrocarbon is even a reliable indicator of paraffin adulteration [19]. 


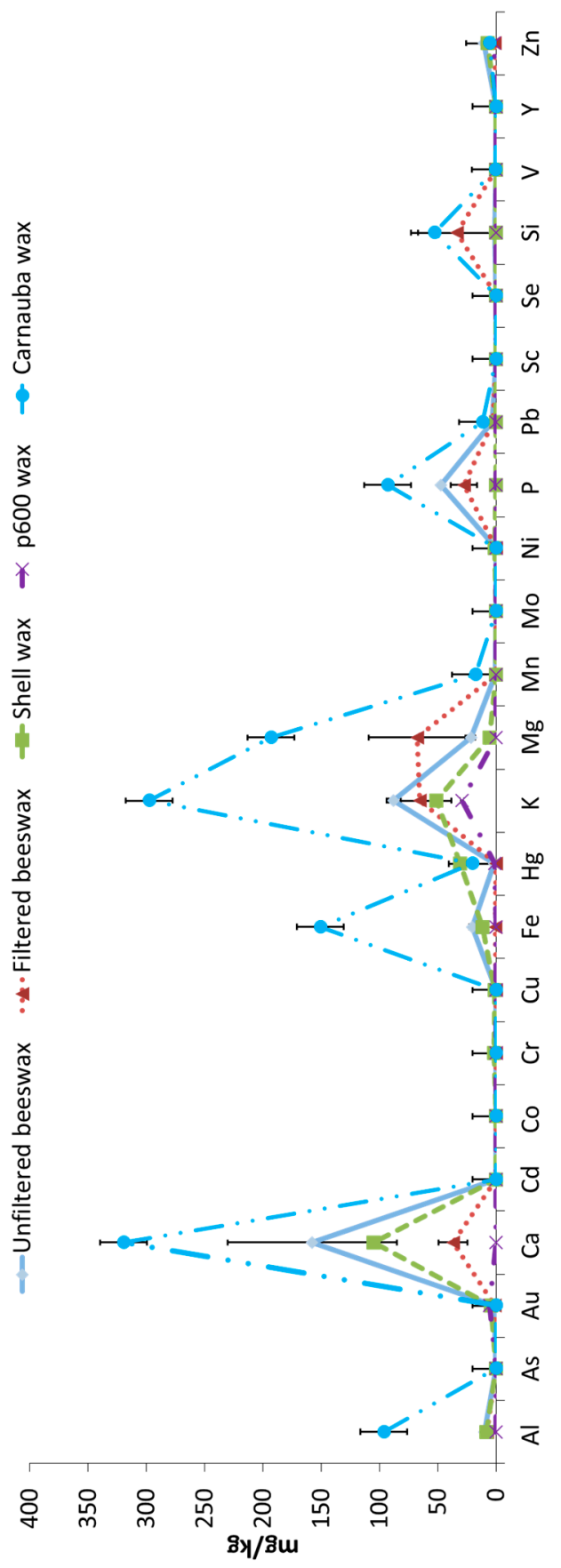

Figure 1. Chemical element profile of beeswax samples before and after the filtration process and of different waxes used for adulteration. Data $(n=3)$ shown as mean \pm SEM for pre-filtered and post-filtered beeswax samples and a single measurement is shown for shell, p600 and carnauba wax.

\subsection{Antioxidant Capacity, Polyphenol and Flavonoid Content in Unfiltered and Filtered Beeswax Samples}

Total antioxidant capacity was measured using the 2,2'-azino-bis(3-ethylbenzothiazoline-6sulphonic acid (ABTS), the ferric reducing antioxidant power (FRAP) and the 2,2-diphenyl-1picrylhydrazyl (DPPH) assays. Total phenolic content was evaluated using the Folin-Ciocalteu's method. Flavonoids content was quantified using a colorimetric method. Results of these three determinations conducted in unfiltered and filtered beeswax samples are shown in Table 5. These determinations were performed separately in lipophilic and hydrophilic extracts instead of in complete beeswax samples. The purpose of this separation was to avoid the underestimation of an extract. In addition, 
analyzing the beeswax extract first would allow the assessment of the potential utility of some of the components of beeswax in biomedical research, similar to what has already been performed with other by-products of the beeswax recycling process [34]. The total antioxidant capacity of the lipophilic extract was reduced roughly in a 45\% when determined using FRAP and DPPH, while a 16\% reduction was obtained when the ABTS method was used. All the results regarding antioxidant capacity of the lipophilic extract differed statistically from the results obtained before the filtration process for each technique. Similar to the total antioxidant capacity, the contents of total phenols and flavonoids were significantly reduced in $64.4 \%$ and $33.5 \%$, respectively $(p<0.05)$. This reduction in antioxidant capacity could be a consequence of the lower content of phenolic compounds and flavonoids present in the samples after the industrial process, which could be retained by the filtration material. In contrast to the lipophilic extract, the parameters measured in the hydrophilic extract were not affected by the filtration process. However, the initial differences between both extracts are very remarkable regarding the antioxidant capacity determined using FRAP and DPPH assays and regarding the flavonoid content. It is evident, given the main lipid nature of the beeswax, that the lipophilic extract showed more antioxidant content and it was the most affected fraction after the filtration process. In view of these results, the possibility of modifying the filtration process should be considered to try to minimize the loss of antioxidants and antioxidant capacity of beeswax. Such modifications could go in several directions, such as changing the temperature or pressure conditions of the filtering process or, more likely, changing the composition or proportion of the filtering materials.

The antioxidant activity of honey could be used to classify its botanical origin [35]. However, as far as we know, this is the first time that these determinations (antioxidant capacity, total phenolics and flavonoids) have been performed in beeswax, and particularly, in its hydrophilic and lipophilic extracts. Therefore, these assessments provide a point of interest in the better characterization of beeswax and its extracts, and open the way for a potential use of some of these extracts in biomedicine.

Table 5. Total antioxidant capacity, polyphenol and flavonoid content in unfiltered and filtered beeswax samples in the lipophilic and hydrophilic extracts $(n=3)$.

\begin{tabular}{|c|c|c|}
\hline & Unfiltered Beeswax & Filtered Beeswax \\
\hline & Mean \pm SEM & Mean \pm SEM \\
\hline & \multicolumn{2}{|c|}{ Lipophilic extract } \\
\hline ABTS $(\mu \mathrm{mol}$ TEq/Kg) & $400 \pm 30$ & $330 \pm 10 *$ \\
\hline FRAP $(\mu \mathrm{mol} \mathrm{TEq} / \mathrm{Kg})$ & $252 \pm 6$ & $133 \pm 5^{*}$ \\
\hline $\mathrm{DPPH}(\mu \mathrm{mol} \mathrm{TEq} / 100 \mathrm{~g})$ & $193 \pm 29$ & $112 \pm 9 *$ \\
\hline Total Phenolic content (mg GAEq/100 g) & $0.20 \pm 0.07$ & $0.07 \pm 0.03 *$ \\
\hline \multirow[t]{2}{*}{ Flavonoids (mg CEq/100 g) } & $1.2 \pm 0.1$ & $0.8 \pm 0.1 *$ \\
\hline & \multicolumn{2}{|c|}{ Hydrophilic extract } \\
\hline ABTS ( $\mu$ mol TEq/Kg) & $260 \pm 10$ & $270 \pm 10$ \\
\hline FRAP ( $\mu$ mol TEq/Kg) & $21.3 \pm 0.4$ & $25.4 \pm 1.2$ \\
\hline $\mathrm{DPPH}(\mu \mathrm{mol} \mathrm{TEq} / 100 \mathrm{~g})$ & $29.6 \pm 11.4$ & $66.2 \pm 26.9$ \\
\hline Total Phenolic content (mg GAEq/100 g) & $0.01 \pm 0.01$ & $0.01 \pm 0.01$ \\
\hline Flavonoids (mg CEq/100 g) & $0.01 \pm 0.01$ & $0.02 \pm 0.01$ \\
\hline
\end{tabular}

$*$ Statistically significant differences $(p<0.05)$ between unfiltered and filtered beeswax. CEq = Catechin equivalents. $\mathrm{GAEq}=$ Gallic acid equivalents. $\mathrm{TEq}=$ Trolox equivalents.

\section{Materials and Methods}

\subsection{Sample Collection}

Beeswax samples were provided by beeswax manufacturers and private beekeepers from different regions of Spain. The samples were maintained at room temperature $\left(20-25^{\circ} \mathrm{C}\right)$ before being analyzed. 


\subsection{Decontamination Procedure}

A total of eight old comb recycled beeswax samples were used; three for the analysis of chlorfenvinphos, three for the analysis of coumaphos and two for the analysis of tau fluvalinate. In all cases, the analyses were performed in duplicate. Beeswax was filtered according to a previously described method [7]. Briefly, beeswax samples were treated with the Norit SA4 PAH activated carbon (Cabot Norit America Inc., Marshall, TX, USA) and the Tonsil 114 FF diatomaceous earth (Süd-Chemie, Moosburg, Germany) in the proportion of 0.04/4.0 wt. beeswax. The filtration time ranges between 40 and $70 \mathrm{~s}$. In the present study, a prototype has been used allowing to work with $500 \mathrm{~kg}$ of beeswax, thus scaling up the one previously described by Bonvehi \& Orantes-Bermejo [7].

\subsection{Extraction and Purification of Acaricide Residues}

An amount of $0.20 \mathrm{~g}$ beeswax and a concentration of triphenyl phosphate (internal standard) referred to the beeswax mass $(2 \mathrm{mg} w / w)$ was dissolved in $3 \mathrm{~mL}$ of hexane in a heating block at $60{ }^{\circ} \mathrm{C}$ for three min. High-molecular weight compounds were eliminated by repeated freezing and centrifugation at $25{ }^{\circ} \mathrm{C}$ for $15 \mathrm{~min}$ at $3300 \times g$ (per triplicate). The purified solution was applied to a Florisil SPE cartridge $(500 \mathrm{mg} / 3 \mathrm{~mL})$ (Waters, Milford, MA, USA). The cartridges were washed with $3 \mathrm{~mL}$ of hexane, and the analytes were eluted with $3 \mathrm{~mL}$ of acetone:hexane (1:1 by volume). The eluate was evaporated to dryness under a nitrogen stream $\left(40^{\circ} \mathrm{C}\right)$; then the dry residue was dissolved in $2 \mathrm{~mL}$ of isooctane and placed in the freezer for at least $30 \mathrm{~min}$ [8].

\subsection{Gas Chromatography-Mass Spectrometry (GC/MS) Analysis of Hydrocarbons and Monoesters}

An amount of 120-140 mg beeswax and a concentration of eicosane (internal standard) referred to the beeswax mass $2.5-3 \%(w / w)$ were dissolved in $2.5 \mathrm{~mL}$ of chloroform. The solution was mechanically shaken to complete dissolution of the beeswax; then the hydrocarbons and monoesters were directly analyzed as previously described [36].

\subsection{ICP-MS Analysis of Chemical Elements}

Samples of beeswax, shell wax, p600 wax and carnauba wax were lyophilized in a vacuum pump (Telstar, Madrid, Spain) and prepared by attack with nitric acid and hydrogen peroxide of supra-pure quality in a microwave digester (Milestone, Sorisole, Italy) for the quantitative determination of metals. Determination of $\mathrm{Mg}$, Al, Si, P, K, Ca, Sc, V, Cr, Mn, Fe, Co, Ni, Cu, Zn, As, Se, Y, Mo, $\mathrm{Cd}, \mathrm{Au}, \mathrm{Hg}$ and $\mathrm{Pb}$ total content in samples was performed using an ICP-MS instrument (Agilent 7500, Agilent Technologies, Tokyo, Japan) coupled with a Meinhard type nebulizer (Glass Expansion, Romainmotier, Switzerland) and equipped with a He collision cell. A Milli-Q system (Millipore, Bedford, MA, USA) was used to obtain deionized water (18 M $\Omega$ ). All reagents used were of the highest available purity. Hydrogen peroxide and nitric acid were of supra-pure quality (Merck, Darmstadt, Germany). A standard solution of $100 \mu \mathrm{g} / \mathrm{L}$ of Li, Mg, Sc, Co, Y, In, Ce, Ba, Pb, Bi, and U in $1 \%(v / v) \mathrm{HNO}_{3}$ was prepared from a $1000 \mathrm{mg} / \mathrm{L}$ multi-element stock standard solution (Merck) and used to optimize the ICP parameters daily. Single-element standard solutions for ICP-MS containing $1000 \mu \mathrm{g} / \mathrm{mL}$ of each analyte were also purchased from Merck. Calibration curves were prepared using Ga as an internal standard and by the dilution of stock solutions of $1000 \mathrm{mg} / \mathrm{L}$ in $1 \% \mathrm{HNO}_{3}$. The accuracy of this method was evaluated by recovery studies after complete digestion of spiked samples with multi-element standards. The calculated recoveries for each element were between $95 \%$ and $105 \%$ in all cases.

\subsection{Isolation of Hydrophilic and Lipophilic Extracts}

Hydrophilic extraction was performed as previously reported [37] by diluting $1 \mathrm{~g}$ of wax in $10 \mathrm{~mL}$ of distilled water and filtering it through Minisart filter of $45 \mu \mathrm{m}$ (Sigma-Aldrich Química SL, Madrid, Spain). Lipophilic extraction was performed as previously reported [38] with some 
modifications. Each sample $(1 \mathrm{~g})$ was vigorously shaken with $10 \mathrm{~mL}$ of n-hexane-acetone mixture (6:4) for $10 \mathrm{~min}$ at room temperature and filtered through Whatman No. 4 filter paper.

\subsection{Measurement of Total Phenolic Content}

The Folin-Ciocalteu method was used to determine the total phenolic content of the hydrophilic and lipophilic extracts obtained from waxes, according to the reported by Singleton et al. [39]. The hydrophilic and lipophilic extracts of each wax $(0.5 \mathrm{~mL})$ were mixed with $2.5 \mathrm{~mL}$ of $0.2 \mathrm{~N}$ Folin-Ciocalteu reagent for five min and $2 \mathrm{~mL}$ of $0.7 \mathrm{M}$ sodium carbonate $\left(\mathrm{Na}_{2} \mathrm{CO}_{3}\right)$. After incubation in the dark at $25^{\circ} \mathrm{C}$ for two hours, the absorbance of the reaction mixture was measured at $760 \mathrm{~nm}$ using a Beckman Du 640 spectrophotometer (Instruments Inc., Fullerton, CA, USA). Gallic acid was used as standard (50-300 mg/L). The total phenolic content was expressed in $\mathrm{mg}$ of gallic acid equivalents $/ 100 \mathrm{~g}$ (mg GAEq/100 g).

\subsection{Measurement of Total Flavonoid Content}

Flavonoid content of the hydrophilic and lipophilic extracts obtained from waxes was determined using a colorimetric method described previously by Chang et al. [40]. Briefly, a sample of $0.25 \mathrm{~mL}$ of the hydrophilic and lipophilic extracts of each sample or (+)-catechin standard solution was mixed with $1.25 \mathrm{~mL}$ of distilled water, followed by the addition of $75 \mu \mathrm{L}$ of a $5 \%$ sodium nitrite $\left(\mathrm{NaNO}_{2}\right)$ solution. After six min, $150 \mu \mathrm{L}$ of a $10 \%$ cadmium chloride hemi-(pentahydrate) solution were added and allowed to settle for another five min before adding $0.5 \mathrm{~mL}$ of $1 \mathrm{M}$ sodium hydroxide. The mixture was completed up to $2.5 \mathrm{~mL}$ with distilled water and mixed well. The absorbance was immediately measured against the blank (the same mixture without the sample) at $510 \mathrm{~nm}$ using a spectrophotometer (Beckman Du 640, USA). (+)-Catechin was used as standard (5-50 mg/L). Total flavonoid content was expressed as mg of (+)-catechin equivalents/100 g (mg CEq/100 g).

\subsection{Quantification of the Total Antioxidant Capacity}

Total antioxidant capacity of the hydrophilic and lipophilic extracts obtained from waxes was assessed using the ABTS, FRAP and the DPPH assays. The ABTS assay was performed according to the modified method of Re et al. [41]. Each sample was analyzed by triplicate and ABTS results are expressed as mmol of Trolox equivalents $/ \mathrm{kg}(\mathrm{mmolTEq} / \mathrm{kg})$. Data are reported as a mean value \pm S.D. for three measurements. The FRAP assay was performed according to the protocol proposed by Benzie \& Strain [42]. Three replicates of each sample were analyzed and FRAP results were expressed as mmol of Trolox equivalents $/ \mathrm{kg}$. The DPPH assay of the hydrophilic and lipophilic extracts obtained from waxes was performed as proposed by Brand-Williams et al. [43]. Results were expressed as $\mu \mathrm{mol}$ of Trolox equivalents/100 g ( $\mu$ molTxEq/100 g).

\subsection{Statistical Analyzes}

Data are presented as mean \pm SEM for a total of three determinations, unless otherwise stated. For each variable, differences between unfiltered and filtered samples were analyzed using Student's $t$ test with the statistical software SPSS 24.0 (IBM, New York, NY, USA).

\section{Conclusions}

The methodology cited here for the decontamination of waxes is a natural alternative to other existing industrial methods. It has a double advantage: (a) it does not contaminate waxes with heavy metals as a result of the process ( $\mathrm{Si}$ and small amounts of As are incorporated into the waxes. The last could be reduced by the election of better diatomaceous earths for the filter); (b) it removes traces of environmental contaminants (heavy metals) that were initially present in the wax $(\mathrm{Al}, \mathrm{Cd}, \mathrm{Pb}, \mathrm{Mn}$ and $\mathrm{Hg}$ ), with the removal of $\mathrm{Mn}$ and the $\mathrm{Hg}$ being statistically significant. In this way, this method allows the revaluation of the use of beeswax in the food industry (as a fruit preservative, etc.), reverting the fall 
of its use in this sector caused by the presence of environmental contaminants (including heavy metals). Moreover, the composition in hydrocarbons and monoesters in the samples was not influenced by the filtration process, although this process significantly reduced the total antioxidant capacity and total phenols and flavonoids content. In addition, this study contributes to a better knowledge and characterization of beeswax, specially related to trace and ultra-trace elements and antioxidant capacity. Additionally, it offers the chance to further develop a method to effectively detect adulterations based on the chemical element profile of wax alone or in combination with other methods.

Author Contributions: J.L.Q., F.J.O.-B. and M.B. designed and supervised the study and looked for funding to execute it. C.T.F.-P. and J.S.-B. developed and performed pesticide analyses. F.G., T.Y.F.-H. and P.R.-R. prepared the extracts and performed the analysis of antioxidant capacity and phenolic content. C.S.-G., J.L. and P.A. performed chemical elements analyzes. A.V.-L. performed statistical analysis and helped with writing the manuscript. M.D.N.-H. performed analyses on hydrocarbons and esters and wrote the original draft of the manuscript. All authors participated in the discussion and revision of the manuscript.

Funding: The present study was partially funded by the "National Beekeeping Aid Program (Programa Nacional de Ayudas a la Apicultura)", cofounded by the European Union and assigned to Spanish FEGA and FEAGA agencies (2016).

Acknowledgments: María Dolores Navarro-Hortal is a FPU fellow from the Spanish Ministry of Ciencia, Innovación y Universidades. We acknowledge Nutraceutical Translations for English language editing of this manuscript.

Conflicts of Interest: The authors declare no conflicts of interest.

\section{References}

1. Tulloch, A.P. Beeswax-composition and analysis. Bee World 1980, 61, 47-62. [CrossRef]

2. Buchwald, R.; Breed, M.D.; Bjostad, L.; Hibbard, B.E.; Greenberg, A.R. The role of fatty acids in the mechanical properties of beeswax. Apidologie 2009, 40, 585-594. [CrossRef]

3. Jiménez, J.J.; Bernal, J.L.; Aumente, S.; del Nozal, M.J.; Martín, M.T.; Bernal, J. Quality assurance of commercial beeswax. Part I. Gas chromatography-electron impact ionization mass spectrometry of hydrocarbons and monoesters. J. Chromatogr. A 2004, 1024, 147-154. [CrossRef] [PubMed]

4. Rosenkranz, P.; Aumeier, P.; Ziegelmann, B. Biology and control of Varroa destructor. J. Invertebr. Pathol. 2010, 103, S96-S119. [CrossRef]

5. Wilmart, O.; Legrève, A.; Scippo, M.L.; Reybroeck, W.; Urbain, B.; de Graaf, D.C.; Steurbaut, W.; Delahaut, P.; Gustin, P.; Nguyen, B.K.; et al. Residues in beeswax: A health risk for the consumer of honey and beeswax? J. Agric. Food. Chem. 2016, 64, 8425-8434. [CrossRef]

6. Cornara, L.; Biagi, M.; Xiao, J.; Burlando, B. Therapeutic properties of bioactive compounds from different honeybee products. Front. Pharmacol. 2017, 8, 412. [CrossRef]

7. Bonvehi, J.S.; Orantes-Bermejo, F.J. Discoloration and adsorption of acaricides from beeswax. J. Food Process Eng. 2017, 40, 1-10. [CrossRef]

8. Serra-Bonvehí, J.; Orantes-Bermejo, J. Acaricides and their residues in Spanish commercial beeswax. Pest Manag. Sci. 2010, 66, 1230-1235. [CrossRef]

9. Calatayud-Vernich, P.; Calatayud, F.; Simó, E.; Picó, Y. Occurrence of pesticide residues in Spanish beeswax. Sci. Total Environ. 2017, 605-606, 745-754. [CrossRef]

10. Calatayud-Vernich, P.; Calatayud, F.; Simó, E.; Picó, Y. Pesticide residues in honey bees, pollen and beeswax: Assessing beehive exposure. Environ. Pollut. 2018, 241, 106-114. [CrossRef] [PubMed]

11. García, M.D.G.; Duque, S.U.; Fernández, A.B.L.; Sosa, A.; Fernández-Alba, A.R. Multiresidue method for trace pesticide analysis in honeybee wax comb by GC-QqQ-MS. Talanta 2017, 163, 54-64. [CrossRef] [PubMed]

12. Mullin, C.A.; Frazier, M.; Frazier, J.L.; Ashcraft, S.; Simonds, R.; vanEngelsdorp, D.; Pettis, J.S. High levels of miticides and agrochemicals in North American apiaries: Implications for honey bee health. PLOS ONE 2010, 5, e9754. [CrossRef] [PubMed]

13. Chauzat, M.P.; Faucon, J.P. Pesticide residues in beeswax samples collected from honey bee colonies (Apis mellifera L.) in France. Pest. Manag. Sci. 2007, 63, 1100-1106. [CrossRef] [PubMed] 
14. Ravoet, J.; Reybroeck, W.; de Graaf, D.C. Pesticides for apicultural and/or agricultural application found in Belgian honey bee wax combs. Bull Environ. Contam. Toxicol. 2015, 94, 543-548. [CrossRef] [PubMed]

15. Perugini, M.; Tulini, S.M.R.; Zezza, D.; Fenucci, S.; Conte, A.; Amorena, M. Occurrence of agrochemical residues in beeswax samples collected in Italy during 2013-2015. Sci. Total Environ. 2018, 625, 470-476. [CrossRef] [PubMed]

16. Yeoh, C.B.; Chong, C.L. Acephate, methamidophos and monocrotophos residues in a laboratory-scale oil refining process. Eur. J. Lipid Sci. Technol. 2009, 111, 593-598. [CrossRef]

17. Van Duijn, G. Industrial experiences with pesticide removal during edible oil refining. Eur. J. Lipid Sci. Technol. 2008, 110, 982-989. [CrossRef]

18. Ruiz Méndez, M.V.; Pérez De La Rosa, I.; Jiménez Márquez, A.; Uceda Ojeda, M. Elimination of pesticides in olive oil by refining using bleaching and deodorization. Food Addit. Contam. 2005, 22, 23-30. [CrossRef]

19. Maia, M.; Nunes, F.M. Authentication of beeswax (Apis mellifera) by high-temperature gas chromatography and chemometric analysis. Food Chem. 2013, 136, 961-968. [CrossRef]

20. Akbari, B.; Gharanfoli, F.; Khayyat, M.H.; Khashyarmanesh, Z.; Rezaee, R.; Karimi, G. Determination of heavy metals in different honey brands from Iranian markets. Food Addit. Contam. Part B Surveill. 2012, 5, 105-111. [CrossRef]

21. Losfeld, G.; Saunier, J.B.; Grison, C. Minor and trace-elements in apiary products from a historical mining district (Les Malines, France). Food Chem. 2014, 146, 455-459. [CrossRef] [PubMed]

22. Zaric, N.M.; Deljanin, I.; Ilijević, K.; Stanisavljević, L.; Ristić, M.; Gržetić, I. Assessment of spatial and temporal variations in trace element concentrations using honeybees (Apis mellifera) as bioindicators. PeerJ 2018, 6, e5197. [CrossRef] [PubMed]

23. Dżugan, M.; Wesołowska, M.; Zaguła, G.; Kaczmarski, M.; Czernicka, M.; Puchalski, C. Honeybees (Apis mellifera) as a biological barrier for contamination of honey by environmental toxic metals. Environ. Monit. Assess. 2018, 190, 101. [CrossRef] [PubMed]

24. Hladun, K.R.; Di, N.; Liu, T.X.; Trumble, J.T. Metal contaminant accumulation in the hive: Consequences for whole-colony health and brood production in the honey bee (Apis mellifera L.). Environ. Toxicol. Chem. 2016, 35, 322-329. [CrossRef] [PubMed]

25. Tlak-Gajger, I.; Kosanović, M.; Bilandžić, N.; Sedak, M.; Čalopek, B. Variations in lead, cadmium, arsenic, and mercury concentrations during honeybee wax processing using casting technology. Arch. Ind. Hyg. Toxicol. 2016, 67, 223-228. [CrossRef] [PubMed]

26. Zarić, N.M.; Ilijević, K.; Stanisavljević, L.; Gržetić, I. Use of honeybees (Apis mellifera L.) as bioindicators for assessment and source appointment of metal pollution. Environ. Sci. Pollut. Res. 2017, 24, 25828-25838. [CrossRef]

27. Hernández, O.M.; Fraga, J.M.G.; Jiménez, A.I.; Jiménez, F.; Arias, J.J. Characterization of honey from the Canary Islands: Determination of the mineral content by atomic absorption spectrophotometry. Food Chem. 2005, 93, 449-458. [CrossRef]

28. Pisani, A.; Protano, G.; Riccobono, F. Minor and trace elements in different honey types produced in Siena County (Italy). Food Chem. 2008, 107, 1553-1560. [CrossRef]

29. Natrass, C.; Horwell, C.J.; Damby, D.E.; Kermanizadeh, A.; Brown, D.M.; Stone, V. The global variability of diatomaceous earth toxicity: A physicochemical and in vitro investigation. J. Occup. Med. Toxicol. 2015, 10, 23. [CrossRef] [PubMed]

30. Redan, B.W.; Jablonski, J.E.; Halverson, C.; Jaganathan, J.; Abdul Mabud, Md.; Jackson, L.S. Factors affecting transfer of the heavy metals arsenic, lead, and cadmium from diatomaceous-earth filter aids to alcoholic beverages during laboratory-scale filtration. J. Agric. Food Chem. 2019, 67, 2670-2678. [CrossRef] [PubMed]

31. Commission Regulation (EU) 2015/1006. Amending Regulation (EC) No 1881/2001 as regards maximum levels of inorganic arsenic in foodstuffs. Off. J. Eur. Union 2015, 161, 14-16.

32. Søvik, E.; Perry, C.J.; Lamora, A.; Barron, A.B.; Ben-Shahar, Y. Negative impact of manganese on honeybee foraging. Biol. Lett. 2015, 11, 20140989. [CrossRef] [PubMed]

33. Jiménez, J.J.; Bernal, J.L.; del Nozal, M.J.; Martín, M.T.; Toribio, L. Identification of adulterants added to beeswax: Estimation of detectable minimum percentages. Eur. J. Lipid Sci. Technol. 2009, 111, 902-911. [CrossRef]

34. Giampieri, F.; Quiles, J.L.; Orantes-Bermejo, F.J.; Gasparrini, M.; Forbes-Hernandez, T.Y.; Sánchez-González, C.; Llopis, J.; Rivas-García, L.; Afrin, S.; Varela-López, A.; et al. Are by-products from beeswax recycling process 
a new promising source of bioactive compounds with biomedical properties? Food Chem. Toxicol. 2018, 112, 126-133. [CrossRef]

35. Dżugan, M.; Tomczyk, M.; Sowa, P.; Grabek-Lejko, D. Antioxidant activity as biomarker of honey variety. Molecules 2018, 23, 2069. [CrossRef] [PubMed]

36. Serra-Bonvehi, J.; Orantes Bermejo, F.J. Detection of adulterated commercial Spanish beeswax. Food Chem. 2012, 132, 642-648. [CrossRef] [PubMed]

37. Giampieri, F.; Gasparrini, M.; Forbes-Hernández, T.Y.; Manna, P.P.; Zhang, J.; Reboredo-Rodríguez, P.; Cianciosi, D.; Quiles, J.L.; Torres Fernández-Piñar, C.; Orantes-Bermejo, F.J.; et al. Beeswax by-products efficiently counteract the oxidative damage induced by an oxidant agent in human dermal fibroblasts. Int. J. Mol. Sci. 2018, 19, 2842. [CrossRef] [PubMed]

38. Ferreira, I.C.F.R.; Aires, E.; Barreira, J.C.M.; Estevinho, L.M. Antioxidant activity of Portuguese honey samples: Different contributions of the entire honey and phenolic extract. Food Chem. 2009, 114, 1438-1443. [CrossRef]

39. Singleton, V.L.; Orthofer, R.; Lamuela-Raventós, R.M. Analysis of total phenols and other oxidation substrates and antioxidants by means of folin-ciocalteu reagent. Methods Enzymol. 1999, 299, 152-178. [CrossRef]

40. Chang, C.C.; Yang, M.H.; Wen, H.M.; Chern, J.C. Estimation of total flavonoid content in propolis by two complementary colorimetric methods. J. Food Drug Anal. 2002, 10, 178-182.

41. Re, R.; Pellegrini, N.; Proteggente, A.; Pannala, A.; Yang, M.; Rice-Evans, C. Antioxidant activity applying an improved ABTS radical cation decolorization assay. Free Radic. Biol. Med. 1999, 26, 1231-1237. [CrossRef]

42. Benzie, I.F.F.; Strain, J.J. The Ferric Reducing Ability of Plasma (FRAP) as a measure of "antioxidant power": The FRAP Assay. Anal. Biochem. 1996, 239, 70-76. [CrossRef] [PubMed]

43. Brand-Williams, W.; Cuvelier, M.E.; Berset, C. Use of a free radical method to evaluate antioxidant activity. LWT 1995, 28, 25-30. [CrossRef]

Sample Availability: Samples of the compounds (unfiltered and filtered beeswaxes) are available from the authors.

(C) 2019 by the authors. Licensee MDPI, Basel, Switzerland. This article is an open access article distributed under the terms and conditions of the Creative Commons Attribution (CC BY) license (http://creativecommons.org/licenses/by/4.0/). 